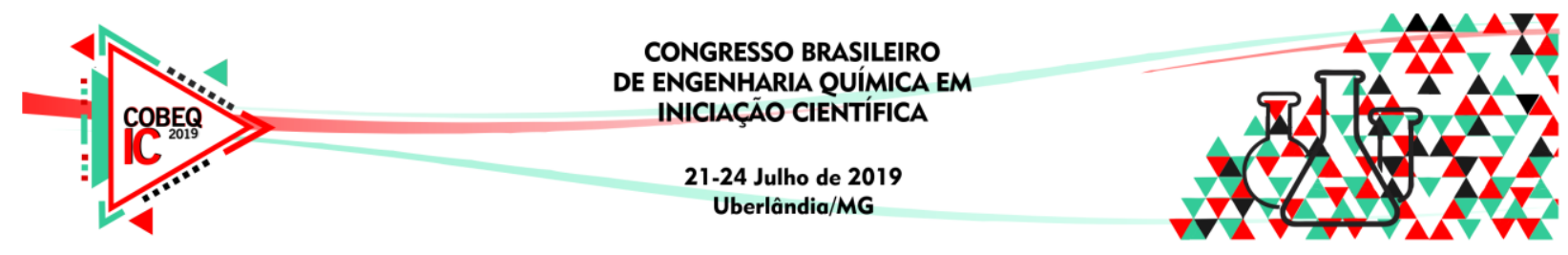

\title{
ESTUDO DA CARACTERIZAÇÃO DO LODO DE ETA VISANDO APLICAÇÃO EM PROCESSOS CATALÍTICOS
}

\author{
G. C. C. $\operatorname{COSTA}^{1}$ e C. D. R. SOUZA ${ }^{1}$ \\ ${ }^{1}$ Universidade Federal do Amazonas, Departamento de Engenharia Química \\ E-mail para contato: geancarloscostaecosta@gmail.com
}

\begin{abstract}
RESUMO - O processo de tratamento de água para consumo, embora fundamental, traz consigo consequências para o ecossistema. O lodo residual gerado nas estações de tratamento é despejado no meio sem receber o devido tratamento, proporcionando consequentes danos ao ecossistema de descarte. Tal resíduo também proporciona riscos à saúde humana devido à presença de microrganismos patogênicos, metais pesados e matéria orgânica. A pesquisa tem como objetivo um estudo da caracterização do lodo estação de tratamento de água visando seu aproveitamento em processos catalíticos. Foram utilizadas as técnicas analíticas de DRX, análise imediata e FTIR. Os resultados mostraram um elevado teor de umidade tornando necessário efetuar tratamento no lodo de ETA para aplicação em combustão direta. Foi identificado também um elevado teor de cinzas indicando alta concentração de materiais inorgânicos como Sílica e Alumina, confirmados por DRX e FTIR, sendo identificada uma composição mineralógica de caulinita e quartzo que dá ao resíduo de ETA um potencial para aplicação e processos catalíticos após tratamento adequado.
\end{abstract}

\section{INTRODUÇÃO}

O processo de tratamento da água é o responsável por garantir a sua qualidade. Durante a coagulação ocorre a geração de resíduo denominado lodo, o qual apresenta em sua composição: matéria orgânica, metais pesados e, segundo Amâncio et al (2017), microrganismos patogênicos. Conforme a NBR 10.004/2004, o lodo de ETA (LETA) é classificado como um resíduo sólido não inerte, se enquadrando em classe II-A. Kloc e Laird (2017) citam que o lodo apresenta características inorgânicas, logo se mostra pouco biodegradável além se ser insolúvel, classificado como fluido não-newtoniano.

Segundo Oliveira et al (2004) e Araujo et al (2015), foram verificados picos de caulinita $\left(\mathrm{Al}_{2} \mathrm{O}_{3} .2 \mathrm{SiO}_{2} .2 \mathrm{H}_{2} \mathrm{O}\right)$, sílica $\left(\mathrm{Si}_{2} \mathrm{O}_{2}\right)$ e gibsita $\left(\mathrm{Al}(\mathrm{OH})_{3}\right)$ por meio de análise de DRX. De acordo com os autores, a composição química do lodo de ETA é composta por $\mathrm{Si}_{2} \mathrm{O}_{2}, \mathrm{Al}_{2} \mathrm{O}_{3}$ e $\mathrm{Fe}_{2} \mathrm{O}_{3}$ os quais correspondem a cerca de $80 \%$.

Noval et al (2016) fala sobre a catálise heterogênea como uma alternativa econômica e estratégia tecnológica quanto aos processos produtivos, garantindo assim uma competitividade. Esses materiais apresentam ampla aplicabilidade, desde processo de produção de biodiesel a sínteses orgânicas. Uma possibilidade de novos catalisadores, é o uso de argilas que apresentam elevada área superficial, pois são propriedades relevantes para a catálise (NYCULYSHYN et al., 2012). 


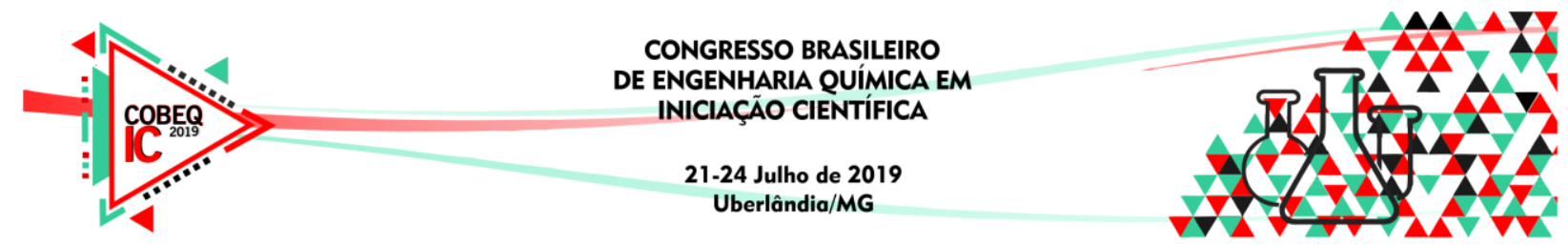

Conforme os trabalhos Oliveira et al (2004) e Araujo et al (2015), o lodo de ETA pode ser considerado um material com características argilosas, portanto Esta pesquisa surge com o objetivo de propor uma nova rota tecnológica para a aplicação do lodo residual das estações de tratamento de água contribuindo, posteriormente, para um processo de purificação de água bruta o qual tenha como base os três pilares do desenvolvimento sustentável (processo economicamente viável, socialmente justo e ambientalmente correto) e, junto a isso, sua aplicação em processos catalíticos após um tratamento adequado.

\section{MATERIAIS E MÉTODOS}

O lodo foi coletado nos decantadores da ETA, no bairro Mauazinho, em Manaus-AM. $\mathrm{O}$ material foi submetido à secagem em estufa à $105^{\circ} \mathrm{C}$ por até 9 horas. Em seguida foi triturado e separado em diferentes granulometrias, em tamisador Bertel a $60 \mathrm{rpm}$ por 15 minutos. O material foi caracterizado por Análise Térmica em um equipamento SDT Q600 da Ta Instrument, a uma taxa de aquecimento de $10^{\circ} \mathrm{C} / \mathrm{min}$, da temperatura ambiente até $950^{\circ} \mathrm{C}$, com fluxo de gás $\mathrm{N}_{2}$ de $30 \mathrm{~mL} / \mathrm{min}$. As características físico-químicas foram obtidas pela Análise Imediata com base na norma NBR 8112 (ABNT, 1986). Para o cálculo do Poder Calorífico Superior foi empregada a equação, segundo Parihk (2005).

A composição foi determinada via Difração de Raios-X (DRX) em um difratômetro EMPYREAN. Utilizou-se também Espectrofotometria de absorção no Infravermelho por transformada de Fourier (FTIR) em um equipamento Shimadzu modelo IRAffunity, com varredura de 4000 a $400 \mathrm{~cm}^{-1}$ e resolução de $2 \mathrm{~cm}^{-1}$. A verificação da porosidade foi feita por Microscopia Eletrônica de Varredura (MEV) em um equipamento OXFORD instrument, modelo XAC, com stubs de alumínio e metalizadas para a captura das imagens.

\section{RESULTADOS E DISCUSSÃO}

No processo inicial de secagem do lodo foram direcionados à estufa 5883,59 g de lodo úmido e, após o processo foram obtidos apenas 1358, $36 \mathrm{~g}$ de lodo seco. Essa massa foi então triturada e encaminhada a análise granulométrica. A distribuição de tamanho das partículas ficou na faixa de $0,045 \mathrm{~mm}$ a $0,850 \mathrm{~mm}$, como podemos verificar na Tabela 1 .

Tabela 1 - Distribuição granulométrica e diâmetro médio de partículas.

\begin{tabular}{|l|l|l|l|l|l|}
\hline Peneira (TY) & xi $(\% 100)$ & $\mathrm{Xi}(\% 100)$ & $-\operatorname{Di}(\mu \mathrm{m})$ & $+\operatorname{Di}(\mu \mathrm{m})$ & $\operatorname{Di}(\mu \mathrm{m})$ \\
\hline 20 & 20,3724 & 79,6276 & 850 & 600 & 725 \\
\hline 28 & 18,4222 & 61,2054 & 600 & 425 & 512,5 \\
\hline 35 & 11,8076 & 49,3978 & 425 & 300 & 362,5 \\
\hline 48 & 11,8341 & 37,5637 & 300 & 250 & 275 \\
\hline 60 & 6,0897 & 31,4740 & 250 & 180 & 215 \\
\hline 80 & 7,5061 & 23,9679 & 180 & 106 & 143 \\
\hline 150 & 8,0987 & 15,8691 & 106 & 75 & 90,5 \\
\hline 200 & 4,8301 & 11,0390 & 75 & 45 & 60 \\
\hline 325 & 5,2394 & 5,7996 & 45 & 38 & 41,5 \\
\hline 400 & 5,7996 & 0,0000 & Fundo & Fundo & 0 \\
\hline
\end{tabular}




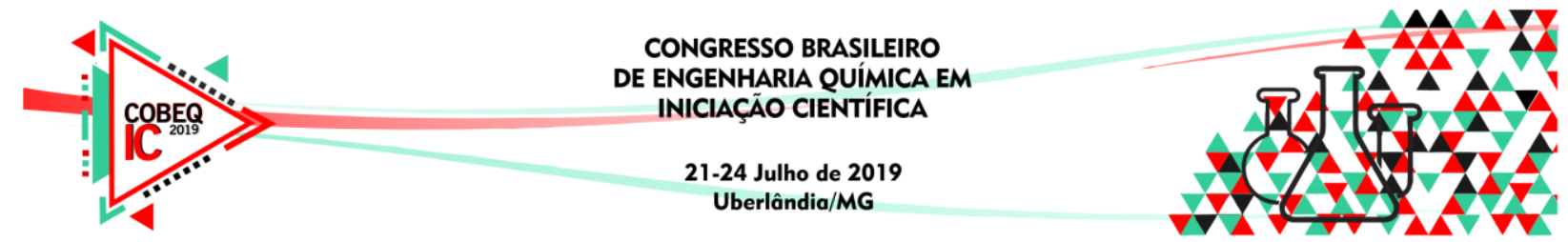

A Figura 1 apresenta a análise térmica efetuada para o lodo de ETA. Podemos notar que ocorre três perdas de massa, tal qual o estudo feito por Oliveira et al (2004). O primeiro evento na curva DTG, a $75,83^{\circ} \mathrm{C}$, está relacionado à perda de água, visto que o lodo adere facilmente à umidade tal qual acontece com materiais argilosos. O pico endotérmico a $465^{\circ} \mathrm{C}$ se refere a uma possível desidroxilação da caulinita. Segundo Paz et al (2010), a transformação da caulinita em metacaulinita ocorre em torno $700^{\circ} \mathrm{C}$. O último pico, na temperatura de $813^{\circ} \mathrm{C}$ pode estar relacionado à quebra da estrutura da metacaulinita formada a partir da desidroxilação.

Figura 1 - Análise térmica do lodo de ETA.

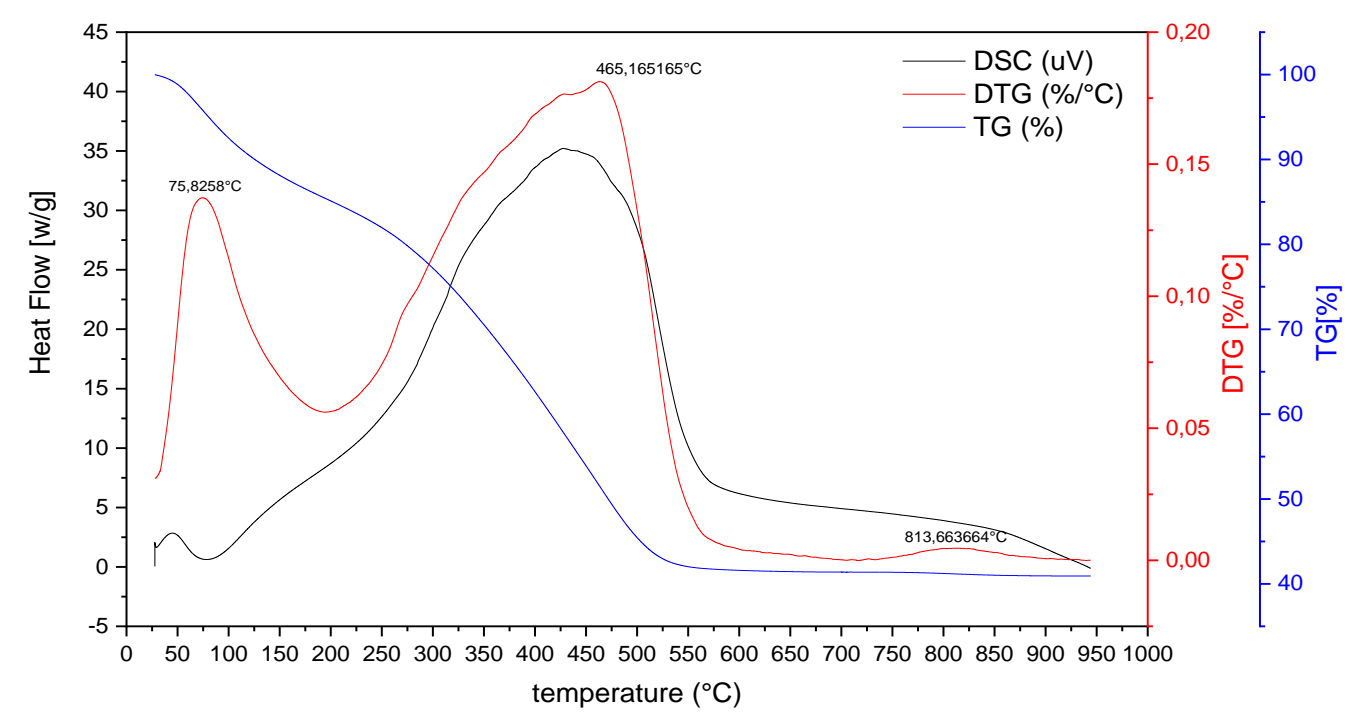

A Figura 2 apresenta a análise de MEV. Os grãos apresentam formatos irregulares e, conforme observado em ambas as micrografias, pode ser notada uma porosidade característica na amostra LETA45 (retido na peneira de $325 \mathrm{TY}$ ), na Figura 2a, a qual apresenta características de silte. Pela Figura $2 \mathrm{~b}$ observa-se que os poros presentes na amostra LETA75 (retido na peneira de $200 \mathrm{TY}$ ) apresenta características de areia fina devido sua classificação granulométrica.

Figura 2 - MEV do lodo de ETA: (a) amostra LETA45 e (b) amostra LETA75.

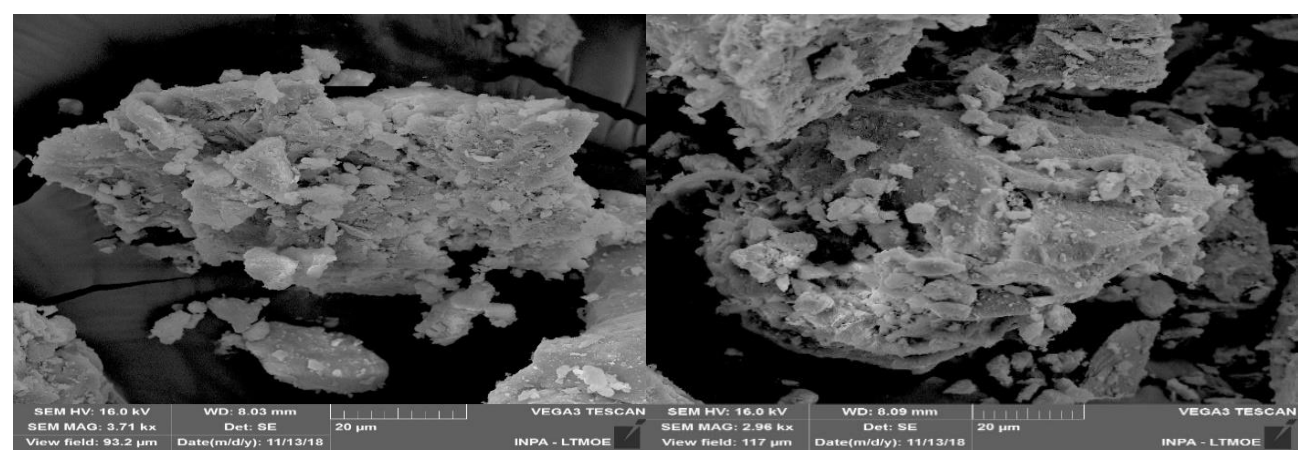

(a)

(b)

Os resultados da Análise Imediata e Poder Calorífico Superior são apresentados na Tabela 2. A umidade, segundo Brand (2010) influi de modo negativo para o processo de 


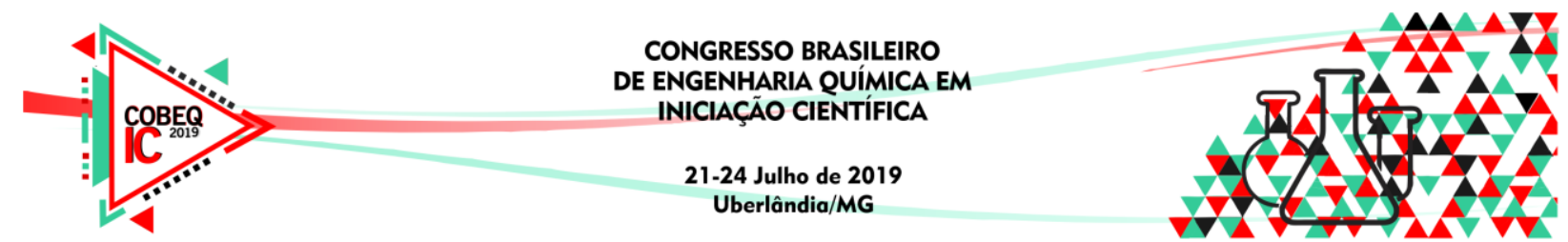

geração de energia de uma biomassa e, Klautau (2008) afirma que para valores acima de 65\% a biomassa é considerada inapropriada para queima direta. O teor de materiais voláteis foi considerado baixo, $14,11 \%$, já que este é responsável por manter as reações de combustão após a volatização dos elementos (Brand, 2010). O elevado teor de cinzas indicou uma grande presença de materiais inorgânicos, o que resulta em baixo potencial para aproveitamento energético se for utilizado sem tratamento. $O$ valor encontrado para o carbono fixo foi elevado, confirmando a não aplicação do lodo de ETA como insumo energético pois, conforme Brand (2010), quanto maior o carbono fixo, mais demorado é o processo de queima. O valor de seu PCS foi obtido conforme o método de Parikh (2005), apresentando valor de 15,48 MJ.kg-1, o qual é muito bom para biomassas destinadas à queima Direta.

Tabela 2 - Dados referentes à análise imediata e PCS.

\begin{tabular}{|c|c|c|}
\hline ANÁLISE & VALOR & UNIDADE \\
\hline \hline Umidade (U) & 76,913 & $\%$ \\
\hline Cinzas (CZ) & 47,29 & $\%$ \\
\hline Materiais Voláteis (MV) & 14,11 & $\%$ \\
\hline Carbono Fixo (CF) & 38,6 & MJ.kg $^{-1}$ \\
\hline
\end{tabular}

A Figura 3 representa o difratograma do lodo de ETA in natura. Os resultados são semelhantes a Oliveira et al (2004) no qual revelaram picos de difração característicos às fases cristalinas de caulinita e quartzo. Para o lodo calcinado, podemos observar a au sência dos picos de caulinita, o que confirma o que fora dito por Oliveira et al (2004) com respeito da desidroxilação da caulinita dando origem à metacaulinita.

Figura 3 - DRX do lodo de ETA in natura e calcinado.

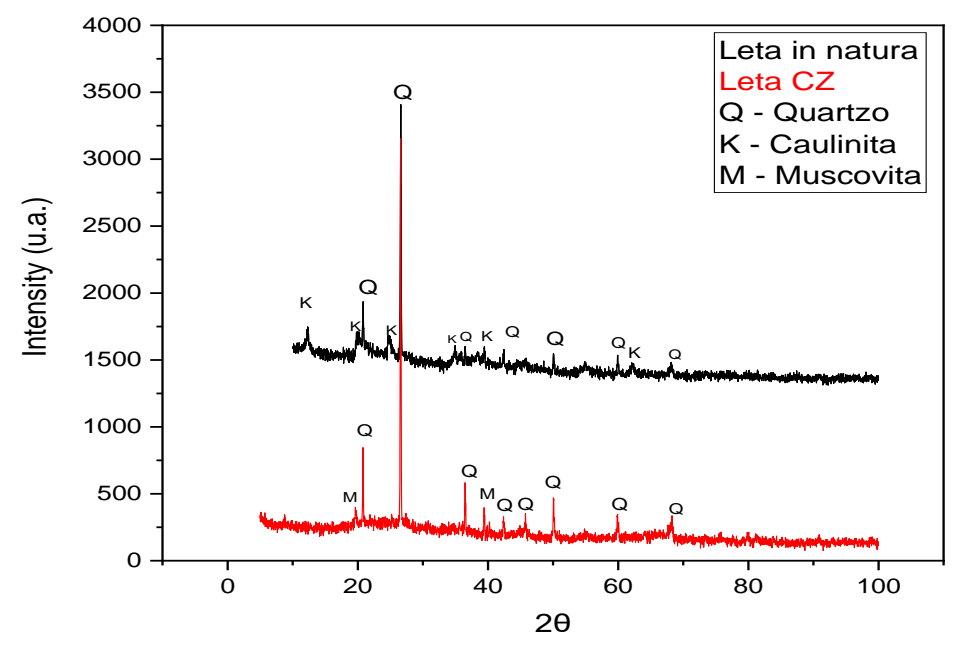

A análise de FTIR é apresentada na Figura 4. No espectro obtido para o lodo in natura foram observadas bandas na faixa de 433 a $914 \mathrm{~cm}^{-1}$. Conforme Machado et al (2018) afirma em seu trabalho que as bandas de Si-O-Si e Si-O-Al são obtidas na faixa de $500-750 \mathrm{~cm}^{-1}$ para materiais argilosos e que existem bandas de $\mathrm{Si}-\mathrm{O}$ em $1030 \mathrm{~cm}^{-1}$ e bandas de $\mathrm{Al}-\mathrm{Al}-\mathrm{OH}$ em 


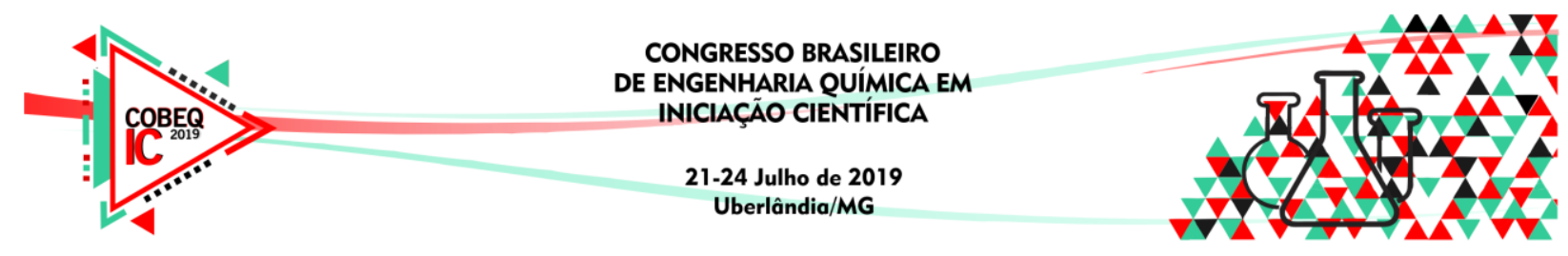

$916 \mathrm{~cm}^{-1}$, assim como bandas próximas à $520 \mathrm{~cm}^{-1}$ características também de $\mathrm{Si}-\mathrm{O}-\mathrm{Al}$. Todas estas bandas são confirmadas na Figura 4.

Figura 4 - Espectro de FTIR do lodo de ETA in natura (linha preta) e calcinado (linha vermelha).

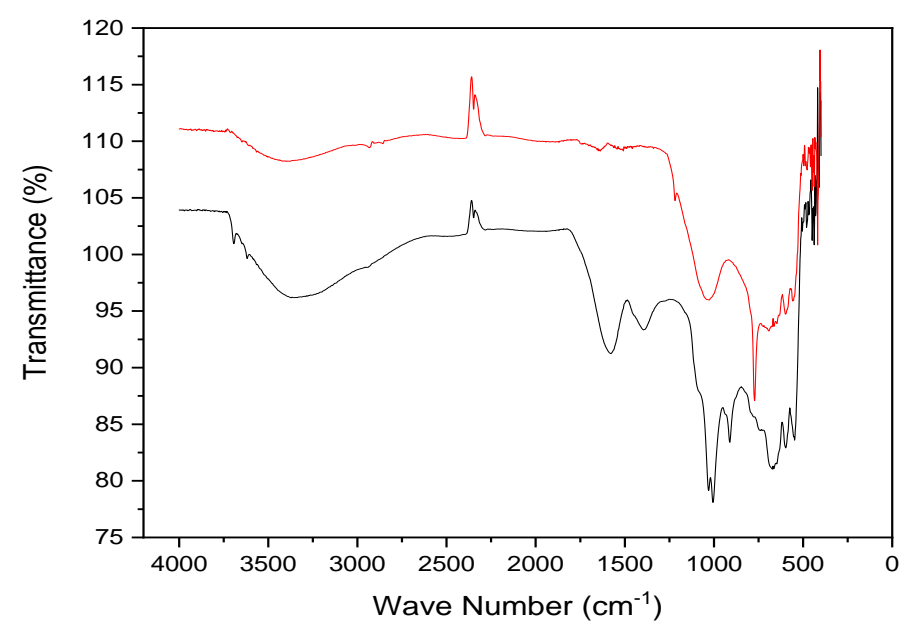

No espectro obtido para o lodo in natura foram observadas bandas na faixa de 433 a $914 \mathrm{~cm}^{-1}$. Conforme Machado et al (2018) afirma em seu trabalho que as bandas de $\mathrm{Si}-\mathrm{O}-\mathrm{Si}$ e Si-O-Al são obtidas nas faixas de $500-750 \mathrm{~cm}^{-1}$ para materiais argilosos e que existem bandas de $\mathrm{Si}-\mathrm{O}$ na faixa de $1030 \mathrm{~cm}^{-1}$ e bandas de Al-Al-OH na faixa de $916 \mathrm{~cm}^{-1}$ e bandas próximas à $520 \mathrm{~cm}^{-1}$ são características de $\mathrm{Si}-\mathrm{O}-\mathrm{Al}$, as quais são confirmadas na Figura 4. Segundo Oliveira et al (2014) bandas de absorção em 3693 e $3620 \mathrm{~cm}^{-1}$, que podem ser atribuídas à deformação axial do grupo estrutural hidroxílico próprio da argila. Para os espectros de FTIR do lodo calcinado, podemos notar que existem bandas na faixa 449 e $774 \mathrm{~cm}^{-1}$ que correspondem à metacaulinita, segundo Paz et al (2010) que as encontrou em 453, 803 e 1063 $\mathrm{cm}^{-1}$. As bandas referentes à sílica permaneceram e novas foram surgindo em $1217 \mathrm{~cm}^{-1}$, semelhante a Capanas (2009).

\section{CONCLUSÃO}

Embora o lodo não apresente potencial para queima direta devido sua elevada umidade e o elevado teor de cinzas, a presença em massa de componentes como silício e alumínio tornam esse resíduo um forte candidato às rotas catalíticas. As análises de DRX e FTIR comprovaram a presença, em larga escala, de quartzo e caulinita no resíduo de ETA. A elevada presença de sílica possibilita uma aplicação na produção de suportes para catalisadores, enquanto a presença da caulinita possibilita a possível síntese de zeólitas. Sendo assim, as diversas técnicas de caracterização indicaram que o lodo de ETA apresenta grande potencial para aplicação em catálise.

\section{REFERÊNCIAS}




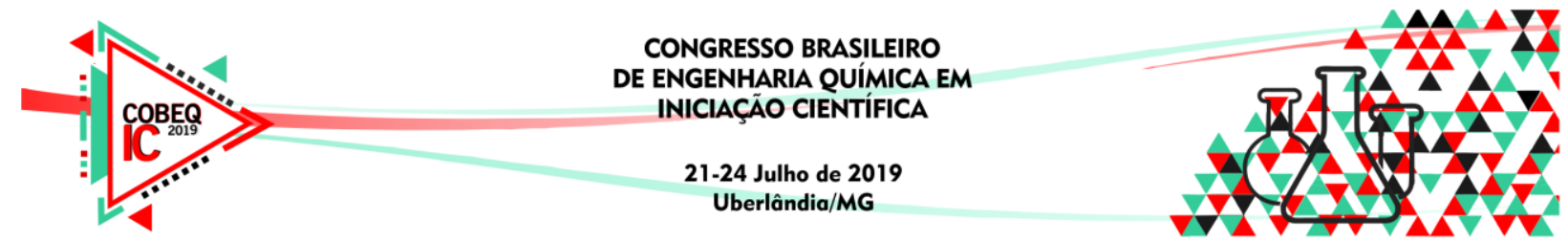

AMÂNCIO, V. D.; RODRIGUES, N. F.; RIBEIRO, D. K.; COELHO, G. Caracterização do lodo gerado numa estação de tratamento de água, Sustentare, Três Corações, v. 1, n. 1, p. 29-44, 2017.

ARAÚJO, F. C.; SCALIZE, P. S.; ALBUQUERQUE A.; ANGELIM, R. R. Caracterização física do resíduo de uma estação de tratamento de água para sua utilização em materiais de construção, Cerâmica, vol.61, no.360, São Paulo, 2015.

BRAND. M. A. Energia de biomassa florestal. Rio de Janeiro: Interciência, 2010.

CAPANAS, S. A. Caracterização e estudo do comportamento térmico de resíduo (lodo) proveniente de estações de tratamento de água e de esgotos do município de araraquarasp. 2009. (Dissertação de mestrado em química analítica), Universidade Estadual Paulista, Instituto de Química. Araraquara. SP. 2009.

NYKULYSHYN, T. I.; VORONCHAK, Z.; RYPKA, A .P. Central Eur. J. Chem. 10 (2012) 1830.

KLAUTAU, J. V. P. Análise Experimental de uma Fornalha a lenha de Fluxo Cocorrente Para Secagem de Grãos. 2008. Dissertação (mestrado em Engenharia de Recursos Hídricos e Ambiental) PPGERHA, Universidade Federal do Paraná. Curitiba, 2008.

KLOC, P. A; LAIRD, V. Y. Avaliação de impacto de lodo de estação de tratamento de água (ETA) na qualidade das águas do arroio pilão de pedra, 2017. 75p. Trabalho de Conclusão de Curso (Bacharelado em Engenharia Química) - Universidade Tecnológica Federal do Paraná. Ponta Grossa, 2016.

MACHADO, P. C. M.; LANBEHN, J. T.; OLIVEIRA, M. C.; ELYSEU, F.; CARGNIN, M.; DE NONI JR, A.; FRIZON, A. E. T.; PETERSON, M. Estudo do comportamento e caracterização de argilas bentoníticas após processo de liofilização. Cerâmica 64 (2018) 207-213.

NBR 8112., carvão vegetal - análise imediata. ABNT, 1986

NOVAL, E. V.; PUENTES, O. C.; CARRIAZO, G. J. Magnetita (Fe3O4): Uma estructura inorgánica com múltiples aplicaciones em catálisis heterogénea. Universidad Nacional de Colombia, 2016

OLIVEIRA, R. I. V.; ROCHA, G. C. M.; VOGAS, C. A.; SILVA, N. L. A.; BERTOLINO, C. L. Caracterização estrutural para argilas bentoníticas para utilização como nanocargas. $21^{\circ}$ Congresso de Engenharia e Ciência dos Materiais, 2014.

OLIVEIRA, S. M. E.; MACHADO, Q. S.; HOLANDA, F. N. J. Caracterização de resíduo (lodo) proveniente de estação de tratamento de águas visando sua utilização em cerâmica vermelha. Cerâmica 50, 324-330, 2004.

PARIKH, J.; CHANNIWALA, S. A.; GHOSAL, G. K. A. correlation for calculating HHV from proximate analysis of solid fuels. Fuel, v. 84, n. 5, p. 487-494. 2005.

PAZ, A. P. S.; ANGÉLICA, S. R.; NEVES, F. R. Síntese hidrotermal de sodalita básica a ártir de um rejeito de caulim termicamente ativado. Quim. Nova, Vol. 33, No. 3, 579-583, 2010 . 